\title{
Oryzalin-induced Chromosome Doubling in Buddleja to Facilitate Interspecific Hybridization
}

\author{
Bruce L. Dunn ${ }^{1,3}$ and Jon T. Lindstrom ${ }^{2}$ \\ Department of Horticulture, University of Arkansas, 316 Plant Sciences \\ Building, Fayetteville, AR 72701 \\ Additional index words. butterfly bush, mitotic inhibitor, breeding, flow cytometry
}

\begin{abstract}
A protocol for producing fertile tetraploid forms of the hybrid Buddleja madagascarensis Lam. $\times$ B. crispa Benth. would enable introgression of orange flower, pubescence, and nondehiscent fruit characteristics found in section Nicodemia (Tenore) Leeuw. into B. davidii Franchet section Buddleja. Excised nodal sections of a single sterile diploid selection from that cross were treated in vitro with 3,5 , or $7 \mu \mathrm{M}$ oryzalin concentrations for 1, 2, or 3 days or were left as an untreated control. A population of plants was generated from these cultures and transferred to the greenhouse. Treated plants were initially screened phenotypically for higher ploidy levels on the basis of stem thickness and leaf size. Those selected based on polyploidy characteristics were subjected to cytometric analysis, confirming that six tetraploid plants were generated. Nodal survival rates were dependent on oryzalin concentration and treatment duration. Significant increases in fertility accompanied polyploidy induction, because crosses between the newly developed tetraploids and $B$. davidii cultivars produced viable fertile plants. Chemical name used: 3,5 -dinitro- $N_{4}, N_{4}$-dipropylsulfanilamide (oryzalin).
\end{abstract}

Buddleja L., commonly known as butterfly bush, encompasses $\approx 125$ species distributed throughout most of the world, including North and South America, Asia, and Africa (Norman, 2000). The majority of the species are either diploid $(2 n=38)$ or tetraploid $(2 n=$ 76), although 16 -ploid $(2 n=304)$ species have been reported (Moore, 1960). Within the tetraploid species, $B$. davidii Franch. and its numerous cultivars are the most important economically, because they are commonly found throughout the nursery trade. Breeders are trying to incorporate useful traits found in other Buddleja species back into B. davidii; however, chromosome number incompatibilities and sterility problems can limit success rate.

Such was the case in 2001, when an original cross made by Raymond Moore in 1949 (reported by Leeuwenberg, 1979) between diploid B. madagascarensis Lam. and the diploid B. crispa Benth was repeated (Renfro, 2004). Hybrids with multiple panicles of dense orange flowers that retained the nondehiscent fruit characteristic resulted from this intersectional cross between $B$. madagascarensis (section Nicodemia) and B. crispa (section Buddleja). Resulting hybrids were sterile; therefore, incorporating its unique traits into $B$. davidii would be difficult. Similar sterility problems were also reported in $\mathrm{F} 1$ progeny after intersectional hybridization of diploids $B$. madagascarensis $\times$

Received for publication 10 Feb. 2007. Accepted for publication 1 May 2007.

${ }^{1}$ Graduate student.

${ }^{2}$ Associate professor.

${ }^{3}$ To whom reprint requests should be addressed; e-mail bldunn@uark.edu.
B. asiatica Lour. (Tobutt and Prevette, 1993). Not all intersectional crosses result in sterile progeny, as Lindstrom et al. (2004) reported fertile progeny resulting from the intersectional cross $B$. indica Lam. (section Nicodemia) by B. davidii 'White Bouquet' (section Buddleja).

Recovering fertility and equalizing chromosome numbers by mitotic polyploidization can be achieved by using mitotic inhibitors. The most commonly used chemical mutagens in horticulture are colchicine and oryzalin. Using colchicine, Rose et al. (2000) produced a tetraploid B. globosa Hope. Colchicine has been used for many years, although oryzalin is proving to be an effective substitute because it was found to be as effective as colchicine at significantly lower concentrations and is less hazardous to human health (Kermani et al., 2003; Morejohn et al., 1987). Both act as spindle inhibitors by disrupting spindle microtubules in mitosis; however, colchicine has been shown to cause mutagenic effects as well (Luckett, 1989; Tambong et al., 1998). Success rate using these chemicals for chromosome doubling varies depending on the plant species, concentration levels, and treatment duration. Restored fertility, increased flower and leaf sizes, and shortened internodes often accompany ploidy manipulation (Pryor and Frazier, 1968).

Plants treated with chemical inhibitors must be screened to identify polyploid plants. Flow cytometry is recognized as a quick way to confirm and sort plants based on relative DNA content of nuclei without having to do labor-intensive and often subjective stomatal or chromosome root-tips counts (Galbraith et al., 1997).
The goal of this research was to determine by flow cytometry if oryzalin could be used to double the chromosomes of an orange-flowered diploid interspecific hybrid (B. madagascarensis $\times B$. crispa) as described by Renfro (2004). The overall objective was to restore the fertility of the sterile hybrid so that novel traits could be introgressed into the cultivated gene pool of $B$. davidii.

\section{Materials and Methods}

Plant material. One selection, 02-25-142, of the cross $B$. madagascarensis $\times B$. crispa was chosen from a hybrid population because of its distinct orange color, flower number, presence of pubescence, sweet scent, and nondehiscent berry fruiting habit.

Tissue culture. Selection 02-25-142 was cultured in 2004 by sterilizing apical shoot tips in a $10 \% \mathrm{v} / \mathrm{v}$ chlorine bleach solution $(0.5 \% \mathrm{w} / \mathrm{v}$ sodium hypochlorite) for $15 \mathrm{~min}$. The tips were then rinsed three times in sterile distilled water and placed in Magenta boxes (Magenta Corp., Chicago) containing $50 \mathrm{~mL}$ of media under sterile conditions. The medium contained Murashige and Skoog plus minimal organics (Murashige and Skoog, 1962), $30 \mathrm{~g} \cdot \mathrm{L}^{-1}$ sucrose, $0.5 \mathrm{~g} \cdot \mathrm{L}^{-1}$ MES (2-N-morpholinoethanesulfonic acid), $400 \mu \mathrm{L}$ $\mathrm{BA}, 1 \mu \mathrm{L}$ NAA, and $6.8 \mathrm{~g} \cdot \mathrm{L}^{-1}$ agar. Both BA and NAA were from $10 \mathrm{~mm}$ stock solutions. The $\mathrm{pH}$ was adjusted to 5.7.

Oryzalin experiment. Oryzalin (PhytoTechnology Laboratory, Shawnee Mission, KS) was dissolved in dimethyl sulfoxide (DMSO) to make a $10 \mathrm{~mm}$ stock solution. A factorial experiment using three different concentrations of oryzalin $(3,5$, and $7 \mu \mathrm{M})$ by three different durations of treatments $(1,2$, and $3 \mathrm{~d}$ ) plus controls (minus oryzalin) was initiated. One liter of media (described previously) was divided into four $250-\mathrm{mL}$ aliquots and autoclaved for $20 \mathrm{~min}$. Each aliquot of media had $0,75,125$, and $175 \mu \mathrm{L}$ of oryzalin and $175,100,50$, and $0 \mu \mathrm{L}$ of DMSO added to each under the flow hood, respectively. Six baby food jars with $30 \mathrm{~mL}$ of medium were filled from each $250-\mathrm{mL}$ jar for a total of 24 jars per experiment. Two of the jars, with five nodes each, were used for each treatment $\times$ duration. Nodal survival rates within the two jars were combined for a single value for each interaction. Beginning 4 Aug. 2004, actively growing nodal sections $(\approx 1 \mathrm{~mm}$ thick and $3 \mathrm{~mm}$ long) of $02-25-142$ with leaves removed were placed on top of the media in each jar for a total of 120 nodes. After the initial exposure to oryzalin, nodal sections were moved to new media without oryzalin. Thereafter, nodal sections were moved to fresh media every 2 weeks for 2 months. Nodal survival rates were then recorded, and those nodal sections failing to form shoots were considered dead. After 2 months, in vitro shoots were dipped in 1000 ppm potassium salt of indole-3-butyric acid (K-IBA) and rooted in a Park Seed Bio Dome and Bio Sponges (Greenwood, SC). Root initiation occurred within 2 weeks, and plants were then acclimated to greenhouse 
conditions. Plants were later phenotypically screened for higher ploidy levels based on increased stem and leaf size. This experiment was repeated three times.

Ploidy assessment. Approximately 100 $\mathrm{mg}$ of fresh leaf tissue was collected and placed in a Petri dish that had $2 \mathrm{~mL}$ of cold $\left(4{ }^{\circ} \mathrm{C}\right)$ chopping buffer. The chopping buffer \{30 mM $\mathrm{MgCl}_{2}, 20 \mathrm{~mm}$ 3- $N$-[Morpholino]propanesulfonic acid (MOPS), $30 \mathrm{~mm}$ sodium citrate, $0.1 \%$ Triton-X 100 , and $2.0 \%$ polyvinylpyrrolidone (PVP-40) $\}$ was modified from Price and Johnston (1996). Leaf tissue was chopped with a razor blade for $1 \mathrm{~min}$ to suspend nuclei. A new blade was used for each sample. The homogenate was then poured through Miracloth (Calbiochem, La Jolla, CA) into a $10-\mathrm{mL}$ beaker. An additional $1 \mathrm{~mL}$ of chopping buffer was used to rinse excess plant material. The filtrate was then poured through a syringe barrel fitted with a 30- $\mu$ M Millipore (Billerica, MA) nylon filter. Samples were centrifuged at $4{ }^{\circ} \mathrm{C}$ for 5 $\mathrm{min}$ at $1000 \mathrm{rpm}$. Supernatant was discarded, and the nuclear pellet was resuspended in 300 $\mu \mathrm{L}$ chopping buffer. Lastly, $10 \mu \mathrm{g} \cdot \mathrm{mL}^{-1}$ of RNase A (Sigma-Aldrich, St. Louis) and 100 ppm propidium iodide (Sigma-Aldrich) was added. The samples were incubated at $4{ }^{\circ} \mathrm{C}$ for $1 \mathrm{~h}$ before analysis with a FACSort flow cytometer (Becton Dickinson Immunocytometry Systems, San Jose, CA) to determine nuclear DNA content. In each sample, the DNA content of 2000 nuclei was checked. Diploid 02-25-142 was used as a control.

Hybridization. Controlled pollinations between the oryzalin-induced tetraploids and $B$. davidii var. nanhoensis 'Alba' (Chitt.) Rehd. and B. davidii var. nanhoensis 'Mongo' were made beginning 4 Aug. 2005. Flowers were emasculated before anthesis, and pollination occurred once a day for $3 \mathrm{~d}$ after emasculation. Mature seeds from these crosses were collected beginning on 11 Nov. 2005 and subsequently sown on 1 Dec. 2005 in pots using a 1:1 ratio of Fafard \#2 (Portland, OR) mix and perlite that had been autoclaved and pretreated with boiling water. Pots were placed in a Park Seed Bio Dome until the seed germinated and then seedlings were acclimated to greenhouse conditions.

Statistics. Nodal survival rates were analyzed by analysis of variance using the PROC GLM Program with MEANS statement of SAS/STAT Software version 8.0 for Windows (SAS Institute Inc., 1989). Means were compared using Fisher's protected least significant difference at $\alpha=0.05$.

\section{Results and Discussion}

In our experimental design, DMSO was added to control treatments to ascertain its effects on chromosome doubling. Chauvin et al. (2003) indicated that some of their tetraploids may have been the result of oryzalin and DMSO acting synergistically, because they lacked DMSO controls. In our study, clearly DMSO alone had no effect on ploidy induction (Table 1) similar to find-
Table 1. Survival rate and number of confirmed tetraploids induced by oryzalin concentrations and treatment durations on nodes of Buddleja madagascarensis $\times$ B. crispa.

\begin{tabular}{lcc}
\hline Experiment & $\begin{array}{c}\text { Survival } \\
\text { mean }^{\mathrm{z}}\end{array}$ & $\begin{array}{c}\text { Confirmed } \\
\text { tetraploids }\end{array}$ \\
\hline Oryzalin concn $(\mu \mathrm{M})$ & $10.0 \mathrm{a}$ & 0 \\
0 & $7.0 \mathrm{~b}$ & 2 \\
3 & $6.4 \mathrm{~b}$ & 3 \\
5 & $6.0 \mathrm{~b}$ & 1 \\
7 & 2.0 & \\
LSD $_{0.05}$ & & \\
Exposure length (days) $_{1}$ & $8.4 \mathrm{a}$ & 1 \\
1 & $7.7 \mathrm{ab}$ & 2 \\
2 & $6.0 \mathrm{~b}$ & 3 \\
3 & 1.8 & \\
LSD $_{0.05}$ &
\end{tabular}

${ }^{\mathrm{z}}$ Means with the same letter are not significantly different $(P<0.05)$ according to Fisher's protected least significant difference $(\mathrm{n}=35)$.

ings of Thao et al. (2003), but its activity in inducing tetraploids when mixed with oryzalin was not tested in that study.

As main factors for determining optimal survival rates, concentrations of oryzalin $(\mathrm{F}$ value $=6.71 ; P=0.002)$ and oryzalin exposure times $(\mathrm{F}$ value $=4.20 ; P=0.028)$ were both significant; however, the interaction between the two was nonsignificant $(\mathrm{F}$ value $=$ $1.25 ; P=0.319$ ). Nodal survival rates in concentrations of oryzalin were not significantly different among oryzalin treatments and averaged $65 \%$; however, all were significantly lower than the no-oryzalin control, which had $100 \%$ survival rates (Table 1). Survival rates would probably increase if nodal sections were rinsed before being moved to new media during the first transfer, but for breeding purposes, this higher selection pressure was adequate to generate a few tetraploids. Survival rates for length of exposure indicated significant differences between 1 - and 3-d concentrations with values of $84 \%$ and $60 \%$ survival, respectively (Table 1 ). An inverse relationship between survival rates and exposure times with prolonged exposure to oryzalin was also noted in rose experiments (Kermani et al., 2003). Exposure time greater than $3 \mathrm{~d}$ may lead to a decrease in survival rate but an increased incidence of tetraploid plants. In this study, a $5-\mu \mathrm{M}$ solution for $3 \mathrm{~d}$ produced the optimal number of tetraploids (Table 1); however, this generalization must take into account that only those plants with clear phenotypic tetraploid traits were screened cytometrically.

Leaf size and stem thickness were the best phenotypic indicators of polyploidy in early stages. Plants could be visually screened as early as 4 months after oryzalin treatment. Leaves had an increased width-to-length ratio that was approximately twice that of control leaves, whereas the stem thickness was twice that of the control (data not shown). Flower size (Fig. 1), internode length, leaf color, stem thickness, and increased pollen production (Fig. 2) could not be used to distinguish polyploid plants at an early stage but were good indicators of polyploidy induction at a later stage. Plants

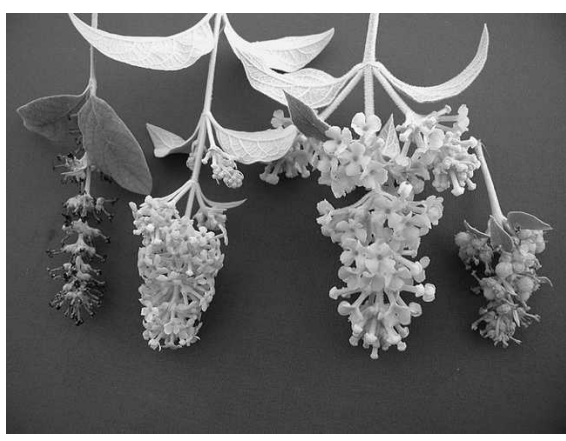

Fig. 1. Inflorescence and fruit characteristics of diploid Buddleja madagascarensis $\times B$. crispa (left) and tetraploid B. madagascarensis $\times$ B. crispa (right).

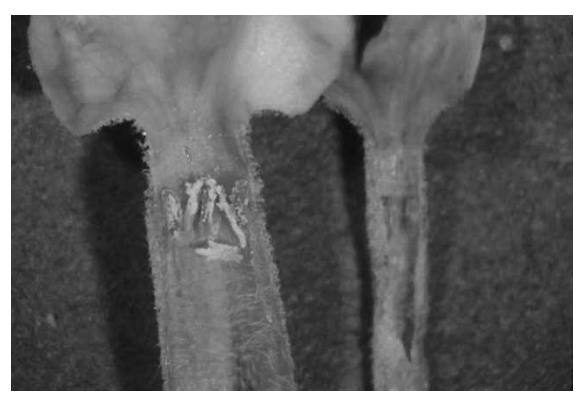

Fig. 2. Pollen and anther appearance of tetraploid Buddleja madagascarensis $\times B$. crispa (left) and diploid $B$. madagascarensis $\times B$. crispa (right).

growing vigorously after treatment were unaffected diploids.

Eight plants exhibited phenotypic characteristics of polyploidy induction at later stages. Flow cytometric profiles showed a significant increase in relative amounts of DNA in nuclei of oryzalin-treated tissues and confirmed the production of six tetraploids and two mixoploids (Fig. 3). Nuclei of diploid plants had relative DNA peak channels ranging from 326 to 360 , and the tetraploid peak channels were roughly double with values of 589 to 724 . Those cytometric profiles with two distinct peaks were considered mixoploids.

Flowering within the tetraploids occurred later than diploids. Flowers of the tetraploid plants were twice the size of the diploid (Fig. 1) and had a more rigid feel to them, contradicting Rose et al. (2000) who reported similar flower size between the diploid and the colchicine-induced tetraploid B. globosa. Anthers from tetraploid plants contained well-developed pollen grains (Fig. 2) and, when treated with a $1 \%$ acetocarmine solution, stained red, indicating viability (data not shown). Diploids had vestigial fruit and seed; however, the induced tetraploid produced a fleshy nondehiscent berry-like capsule containing viable wingless seeds.

Reciprocal crosses between the oryzalininduced tetraploids and $B$. davidii var. nanhoensis 'Alba' and B. davidii var. nanhoensis 'Mongo' were successful in generating a population of viable fertile offspring (Fig. 4). 

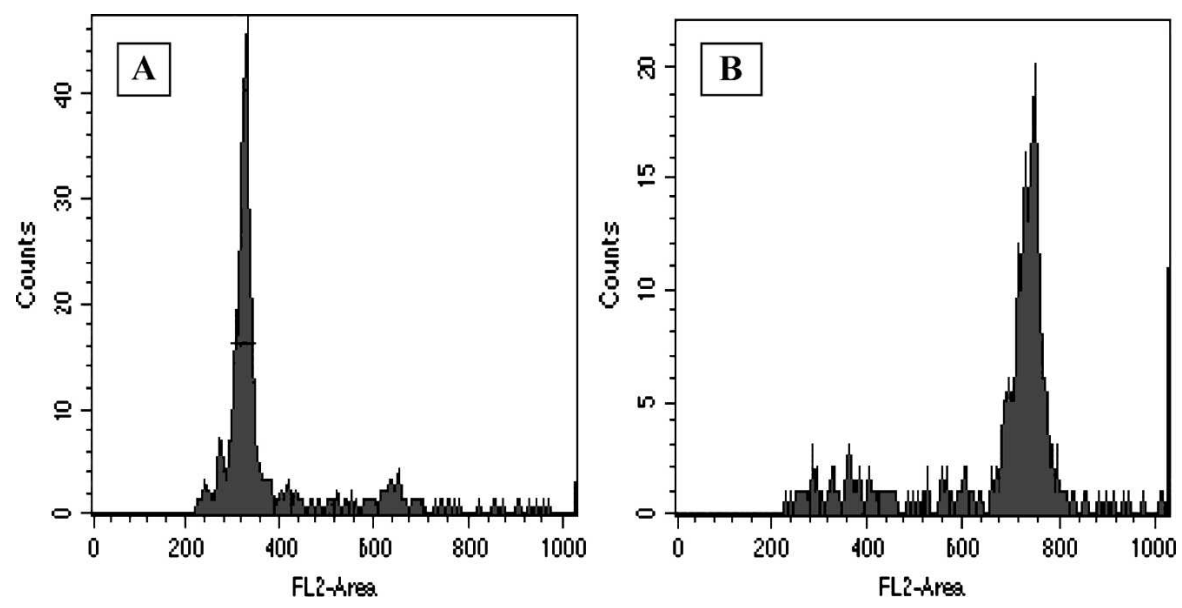

Fig. 3. Estimation of nuclear DNA content using flow cytometry. The relative DNA fluorescence per nuclei is given in the $\mathrm{x}$-axis and the number of corresponding nuclei per fluorescence channel given in the $\mathrm{y}$-axis. (A) Analysis of nuclei isolated from diploid Buddleja madagascarensis $\times$ B. crispa. (B) Analysis of nuclei isolated from oryzalin-treated $B$. madagascarensis $\times B$. crispa.

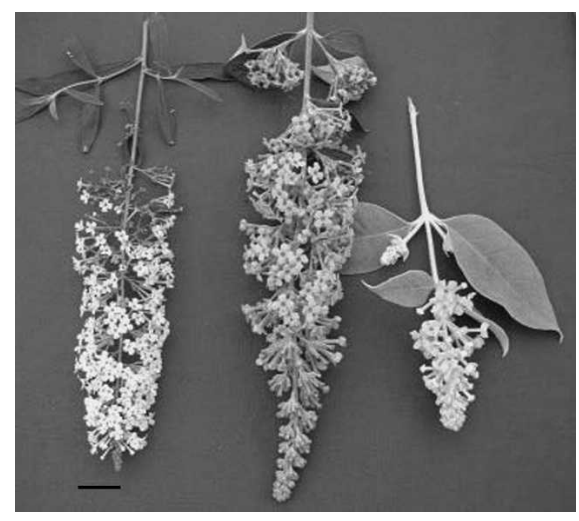

Fig. 4. Representative hybrid (middle) resulting from crossing B. davidii var. nanhoensis 'Alba' (left) with tetraploid Buddleja madagascarensis $\times$ B. crispa (right). Bar $=10 \mathrm{~mm}$.

Number of resulting seedlings from the crosses ranged from 1 to 20 hybrids dependent on which oryzalin-induced tetraploid parent was used and the direction of the cross (data not shown). The use of $B$. davidii var. nanhoensis species as the female resulted in greater seedling numbers. Seedlings resulting from $B$. davidii var. nanhoensis 'Alba' crosses varied in segregation ratios for white and colored flowers (data not shown). Among populations of at least two seedlings, the ratios were as low as 1:9 and as high as 1:3. Three of the five crosses had a 1:1 ratio, which is consistent with the finding of Tobutt (1993) indicating that B. davidii var. nan- hoensis 'Alba' is homozygous-dominant (Alb-1 Alb-1) for the one loci and heterozygous (Alb-2 alb-2) for the other loci controlling flower color. Those crosses not matching the 1:1 ratio are probably attributable to small population numbers. All crosses are currently being field evaluated for presence of pubescence, flower color, nondehiscent fruit, and seed characteristics.

This study demonstrated for the first time that oryzalin was effective in inducing polyploidy in Buddleja. Along with changing ploidy levels, oryzalin could be used to restore fertility and alter morphological traits such as flower size or growth habit in other Buddleja species. Greater chromosome doubling potential can be achieved when concentrations and length of exposure are optimized. With the success of tetraploid induction, it should be possible to produce a bicolored orange-flowered $B$. davidii hybrid hardy in U.S. Dept. of Agriculture zones 7 through 10.

\section{Literature Cited} Ellisseche. 2003. Chromosome doubling of $2 x$ Solanum species by oryzalin: Method development and comparison with spontaneous chromosome doubling in vitro. Plant Cell Tissue Organ Cult. 73:65-73.

Galbraith, D.W., G.M. Lambert, J. Macas, and J. Dolezel. 1997. Analysis of nuclear DNA content and ploidy in higher plants, p. 7.6.1-7.6.22. In: Robinson, J.P. (ed.). Current protocols in cytometry. Wiley, New York.
Chauvin, J.E., C. Souchet, J.P. Dantec, and D.
Kermani, M.J., V. Sarasan, and A.V. Roberts. 2003. Oryzalin-induced chromosome doubling in Rosa and its effects on plant morphology and pollen viability. Theor. Appl. Genet. 107:1195-1200.

Leeuwenberg, A.J.M. 1979. The Loganiaceae of Africa XVIII. Buddleja II. Revision of the African and Asiatic species. Meded. Landbouwhogeschool 79:1-163.

Lindstrom, J.T., G.T. Bujarski, and B.M. Burkett. 2004. A novel intersectional Buddleja hybrid. HortScience 39:642-643.

Luckett, D. 1989. Colchicine mutagenesis is associated with substantial heritable variation in cotton. Euphytica 42:177-182.

Moore, R.J. 1960. Cytotaxonomic notes on Buddleja. Amer. J. Bot. 47:511-517.

Morejohn, L.C., T.E. Bureau, T. Mole-Bajer, A.S. Bajor, and D.E. Fosket. 1987. Oryzalin, a dinitroaniline herbicide, binds to plant tubulin and inhibits microtubule polymerization in vitro. Planta 172:252-264.

Murashige, T. and F. Skoog. 1962. A revised medium for rapid growth and bio-assays with tobacco tissue cultures. Physiol. Plant. 15:473479.

Norman, E. 2000. Buddlejaceae. Flora Neotropica Monogr. 81, New York Botanical Garden, Bronx.

Price, H.J. and J.S. Johnston. 1996. Analysis of plant DNA content by Fuelgen micro spectrophotometry and flow cytometry, p. 115132. In: Jauhur, P. (ed.). Methods of genome analysis in plants: Their merits and pitfalls. CRC Press, Boca Raton, FL.

Pryor, R.L. and L.C. Frazier. 1968. Colchicineinduced tetraploid azaleas. HortScience 3:283286.

Renfro, S. 2004. Artificial hybridization: Intersectional and interspecific breeding among Asiatic and Neotropical Buddleja species. University of Arkansas, Fayetteville. MS Thesis.

Rose, J.B., J. Kubba, and K.R. Tobutt. 2000 Induction of tetraploidy in Buddleia globosa. Plant Cell Tissue Organ Cult. 63:121-125.

SAS Institute Inc. 1989. SAS/STAT user's guide, Version 6 4th ed., Vol. 2. SAS Inst., Cary, NC.

Tambong, J.T., V.T. Sapra, and S. Garton. 1998. In vitro induction of tetraploids in colchicinetreated cocoyam plants. Euphytica 104:191197.

Thao, N., K. Ureshino, I. Miyajima, Y. Ozaki, and H. Okubo. 2003. Induction of tetraploids in ornamental Alocasia through colchicine and oryzalin treatments. Plant Cell Tissue Organ Cult. 72:19-25.

Tobutt, K.R. 1993. Inheritance of white flower colour and congested growth habit in certain Buddleia progenies. Euphytica 67: 231-235.

Tobutt, K.R. and J.Y. Prevette. 1993. Reciprocal differences in Buddleia $\times$ lewisiana. Plantsman 15:111-114 